\title{
Establishing lung gas volumes at birth: interaction between positive end-expiratory pressures and tidal volumes in preterm rabbits
}

\author{
Kevin Wheeler ${ }^{1-3}$, Megan Wallace ${ }^{1,4}$, Marcus Kitchen ${ }^{5}$, Arjan te Pas ${ }^{1,6}$, Andreas Fouras ${ }^{7}$, Muhammad Islam ${ }^{5}$, Melissa Siew ${ }^{1,4}$, \\ Robert Lewis ${ }^{5}$, Colin Morley ${ }^{2}$, Peter Davis ${ }^{2,8}$ and Stuart Hooper ${ }^{1,2,4}$
}

BACKGROUND: We investigated the effects of positive endexpiratory pressure (PEEP) and tidal volume $\left(\mathrm{V}_{T}\right)$ on lung aeration, pulmonary mechanics, and the distribution of ventilation immediately after birth using a preterm rabbit model.

METHODS: Sixty preterm rabbits (27 d) received volumetargeted positive pressure ventilation from birth, with one of the 12 combinations of PEEP $\left(0,5,8\right.$, or $\left.10 \mathrm{cmH}_{2} \mathrm{O}\right)$ and $\mathrm{V}_{\mathrm{T}}(4,8$, or $12 \mathrm{ml} / \mathrm{kg}$ ). Outcomes included functional residual capacity (FRC), peak inflating pressure (PIP), dynamic compliance (Cd), and distribution of ventilation.

RESULTS: Increasing PEEP from 0 to $10 \mathrm{cmH}_{2} \mathrm{O}$ increased FRC by $4 \mathrm{ml} / \mathrm{kg}$, increased $\mathrm{Cd}$ by $0.2 \mathrm{ml} / \mathrm{kg} / \mathrm{cmH}_{2} \mathrm{O}$, and reduced PIP by $5 \mathrm{cmH}_{2} \mathrm{O}$. Increasing $\mathrm{V}_{\mathrm{T}}$ from 4 to $12 \mathrm{ml} / \mathrm{kg}$ increased FRC by $2 \mathrm{ml} / \mathrm{kg}$, increased $\mathrm{Cd}$ by $0.3 \mathrm{ml} / \mathrm{kg} / \mathrm{cmH}_{2} \mathrm{O}$, and increased PIP by $4 \mathrm{cmH}_{2} \mathrm{O}$. No effect of $\mathrm{V}_{\mathrm{T}}$ on FRC occurred at 0 or 5 PEEP, and no effect of PEEP occurred at $V_{T}=4 \mathrm{ml} / \mathrm{kg}$. At 0 PEEP, increasing $V_{T}$ increased the proportion of gas entering the smaller apical regions, whereas at 10 PEEP, increasing $V_{T}$ increased the proportion of gas entering basal regions, from $47 \%$ to $63 \%$.

CONCLUSION: Both PEEP and $\mathrm{V}_{\mathrm{T}}$ have independent, additive effects on FRC, lung mechanics, and the distribution of ventilation during the immediate newborn period.

A pproximately 1 in 15 infants receive positive pressure ventilation (PPV) at birth (1). In particular, preterm infants commonly require PPV support as they must clear their airways of liquid and establish and maintain a functional residual capacity (FRC), despite having weak inspiratory efforts. Data to guide recommendations for respiratory support immediately after preterm delivery are needed because of the potential to injure the immature lung (2). PPV with a high tidal volume $\left(\mathrm{V}_{\mathrm{T}}\right)$ causes lung injury (3-6) as does PPV of poorly aerated lungs (7). Providing positive end-expiratory pressure (PEEP) immediately after birth quickly improves oxygenation (8) and the establishment of an FRC (9). However, the optimal PEEP required during resuscitation of very preterm infants is not known. Similarly, it is not known whether the optimal level of PEEP varies depending on the $V_{T}$.

The physiological mechanisms involved with lung aeration and the clearance of fetal lung liquid from the airways are complex, and include peripartum factors, epithelial sodium channels, and transepithelial pressure gradients depending on the timing and mode of delivery (10-18). However, after birth, spontaneously breathing infants inhale air into their lungs and establish FRC by generating a subatmospheric intrathoracic pressure (19). This creates a pressure gradient that facilitates the movement of liquid across the distal airways into the surrounding tissue (19), from where it is cleared $(13,20)$. Because hydrostatic pressure gradients facilitate lung aeration, we investigated the effect of PEEP and sustained inflations on lung aeration at birth in preterm rabbits $(9,21,22)$ using synchrotron-based imaging techniques (23). These studies demonstrated that both pressure and the time over which the pressure is applied (pressure-time integral) are important for facilitating and maintaining FRC immediately after birth. During newborn resuscitation, clinicians may increase the peak inflating pressure (PIP) to increase the $V_{T}$ if a baby does not respond to inflations at the starting PIP. In this study, we hypothesized that the $\mathrm{V}_{\mathrm{T}}$ used during resuscitation will also influence FRC accumulation after birth and will have a synergistic effect with PEEP. Specifically, we investigated the interacting effects of PEEP and $\mathrm{V}_{\mathrm{T}}$ on FRC, ventilation parameters, and the homogeneity of tidal ventilation during the initial inflations after birth in preterm rabbits.

\section{RESULTS}

In total, 62 pups were studied although two were ventilated at the wrong settings and were excluded from the analysis, leaving 60 pups (five per group). Imaging data were not available for 3 of 60 pups owing to a failure of the microprocessor-controlled imaging camera, corruption of a data file, or failure of the X-ray shutter to open. The nonimaging data from these pups have been included. Of the 57 pups with video data, all were alive at

'The Ritchie Centre, Monash Institute for Medical Research, Monash University, Melbourne, Australia; ${ }^{2}$ Newborn Research, Royal Women's Hospital, Melbourne, Australia; ${ }^{3}$ Murdoch Children's Research Institute, Melbourne, Australia; ${ }^{4}$ Department of Obstetrics and Gynaecology, Monash University, Melbourne, Australia; ${ }^{5}$ School of Physics, Monash Centre for Synchrotron Science, Melbourne, Australia; ${ }^{6}$ Division of Neonatology, Leiden University Medical Center, Leiden, The Netherlands; ${ }^{7}$ Division of Biological Engineering, Monash University, Melbourne, Australia; ${ }^{8}$ Department of Obstetrics and Gynaecology, University of Melbourne, Melbourne, Australia. Correspondence: Kevin Wheeler (kevin.wheeler@dhhs.tas.gov.au) 
the end of the experiment as determined by visualization of a heartbeat. All had a detectable heartbeat at the start of the experiment except for one ( $\left.\mathrm{PEEP}=0 \mathrm{cmH}_{2} \mathrm{O}, \mathrm{V}_{\mathrm{T}}=4 \mathrm{ml} / \mathrm{kg}\right)$, in which no heartbeat could be detected until after the lung had partially aerated. No pups established regular breathing.

The mean (SD) weight of the 60 pups analyzed was 23 (4) g and all were $27 \mathrm{~d}$ gestational age, with no differences between groups in weight or birth order. None of the pups developed pneumothoraces during the course of this experiment; this was visualized from the phase contrast X-ray imaging.

Analysis of the data for inflations 40-160 showed that the real-time assessment of $\mathrm{V}_{\mathrm{T}}$ overestimated the actual $\mathrm{V}_{\mathrm{T}}$. This overestimation resulted from a minor bounce in the plethysmograph trace during expiration. Pups in the $4 \mathrm{ml} / \mathrm{kg}$ groups received a mean $(\mathrm{SD})$ actual $\mathrm{V}_{\mathrm{T}}$ of $3(0.5) \mathrm{ml} / \mathrm{kg}$; the $8 \mathrm{ml} / \mathrm{kg}$ group received $6.4(0.6) \mathrm{ml} / \mathrm{kg}$; and the $12 \mathrm{ml} / \mathrm{kg}$ group received $9.9(0.8) \mathrm{ml} / \mathrm{kg}$. These differences were consistent across groups. PEEP was delivered accurately.

\section{Changes in FRC}

The FRC at 40, 80, 120, and 160 inflations $\left(\mathrm{FRC}_{160}\right)$ is shown in Table 1 and Figure 1. Plethysmograph data from two outliers were excluded because FRC measurements were outside the mean plus three SDs and measurements were not consistent with the imaging data. After 160 inflations, FRC was $<3 \mathrm{ml} / \mathrm{kg}$ at PEEP 0 and $5 \mathrm{cmH}_{2} \mathrm{O}$ irrespective of the $\mathrm{V}_{\mathrm{T}}$. FRC increased at PEEP 8 and $10 \mathrm{cmH}_{2} \mathrm{O}$; at these higher PEEPs, $\mathrm{V}_{\mathrm{T}}$ had an additive effect, with a maximum FRC of $9.6 \mathrm{ml} / \mathrm{kg}$ at PEEP 10 and $\mathrm{V}_{\mathrm{T}}=12 \mathrm{ml} / \mathrm{kg}$. Regression coefficients are shown in

Table 1. Functional residual capacity

\begin{tabular}{lcccc}
\hline & & \multicolumn{3}{c}{$\mathrm{FRC}(\mathrm{ml} / \mathrm{kg})$} \\
\cline { 2 - 5 } & Inflation & $\mathrm{V}_{\mathrm{T}} 4$ & $\mathrm{~V}_{\mathrm{T}} 8$ & $\mathrm{~V}_{\mathrm{T}} 12$ \\
\hline PEEP 0 & 40 & $0.6(0.4)^{\mathrm{a}}$ & $0.4(0.2)^{\mathrm{a}}$ & $0.3(0.1)$ \\
& 80 & $1.0(0.5)^{\mathrm{a}}$ & $0.5(0.3)^{\mathrm{a}}$ & $0.5(0.2)$ \\
PEEP 5 & 120 & $1.6(0.8)^{\mathrm{a}}$ & $0.6(0.4)^{\mathrm{a}}$ & $1.3(0.5)$ \\
& 160 & $2.4(1.1)^{\mathrm{a}}$ & $0.7(0.3)^{\mathrm{a}}$ & $1.4(0.5)$ \\
& 40 & $1.0(0.4)$ & $1.1(0.4)$ & $1.3(0.8)$ \\
PEEP 8 & 80 & $1.8(0.4)$ & $1.9(0.5)$ & $2.3(0.9)$ \\
& 120 & $2.3(0.2)$ & $2.3(0.5)$ & $2.6(0.8)$ \\
& 160 & $3.0(0.4)$ & $2.9(0.7)$ & $2.8(0.9)$ \\
& 40 & $1.4(0.3)$ & $2.0(0.3)$ & $2.1(0.6)$ \\
PEEP 10 & 80 & $1.6(0.3)$ & $3.3(0.9)$ & $3.3(0.8)$ \\
& 120 & $1.8(0.4)$ & $4.2(1.1)$ & $4.3(0.9)$ \\
& 160 & $2.0(0.4)$ & $5.4(1.4)$ & $5.2(0.9)$ \\
& 40 & $1.8(0.2)$ & $2.5(0.4)$ & $3.8(0.9)$ \\
& 80 & $2.2(0.3)$ & $3.5(0.5)$ & $7.2(1.6)$ \\
& 120 & $2.6(0.4)$ & $4.2(0.6)$ & $8.9(1.9)$ \\
& 160 & $3.3(0.6)$ & $4.8(0.8)$ & $9.6(2.1)$ \\
& 40 & &
\end{tabular}

Data shown as mean (SE). $n=5$ per group.

FRC, functional residual capacity; PEEP, positive end-expiratory pressure; $V_{T}$, tidal volume.

$\mathrm{a} n=4$.
Table 2. Overall, the effect of increasing PEEP from 0 to 10 $\mathrm{cmH}_{2} \mathrm{O}$ was to increase $\mathrm{FRC}$ by $4 \mathrm{ml} / \mathrm{kg}(P<0.001)$. Increasing $\mathrm{V}_{\mathrm{T}}$ from 4 to $12 \mathrm{ml} / \mathrm{kg}$ increased $\mathrm{FRC}$ by $2 \mathrm{ml} / \mathrm{kg}(P=0.01)$. In this model, to obtain an FRC at inflation $160 \mathrm{of}>5 \mathrm{ml} / \mathrm{kg}$, the PEEP needed to be $\geq 8 \mathrm{cmH}_{2} \mathrm{O}$ with a $\mathrm{V}_{\mathrm{T}} \geq 8 \mathrm{ml} / \mathrm{kg}$.

\section{PIPs}

During the experiment, the PIP was altered to deliver the target $\mathrm{V}_{\mathrm{T}}$. The PIPs are summarized in Table 3 and Figure 2. The rate of weaning PIP is not shown, but varied considerably between pups. The initial PIP (PIP init $_{\text {) }}$ ) was $39-42 \mathrm{cmH}_{2} \mathrm{O}$ for all groups except where higher $\mathrm{V}_{\mathrm{T}} \mathrm{s}$ were used in the lower PEEP groups. The highest PIP needed was $45 \mathrm{cmH}_{2} \mathrm{O}$ in the PEEP = $0 \mathrm{cmH}_{2} \mathrm{O}, \mathrm{V}_{\mathrm{T}}=12 \mathrm{ml} / \mathrm{kg}$ group.

Using linear regression (Table 2), the effect of increasing PEEP from 0 to $10 \mathrm{cmH}_{2} \mathrm{O}$ was to decrease $\mathrm{PIP}_{\text {init }}$ by 2.6 $\mathrm{cmH}_{2} \mathrm{O}(P=0.01)$. The effect of increasing $\mathrm{V}_{\mathrm{T}}$ from 4 to $12 \mathrm{ml} /$ $\mathrm{kg}$ was to increase $\mathrm{PIP}_{\text {init }}$ by $3.2 \mathrm{cmH}_{2} \mathrm{O}(P=0.01)$.

By inflation 160, the PIP ( $\left.\mathrm{PIP}_{160}\right)$ was $10 \mathrm{cmH}_{2} \mathrm{O}$ lower than

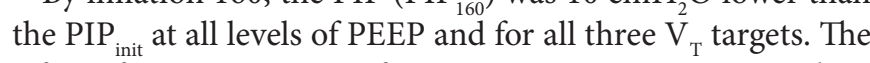
effect of increasing PEEP from 0 to $10 \mathrm{cmH}_{2} \mathrm{O}$ was to reduce

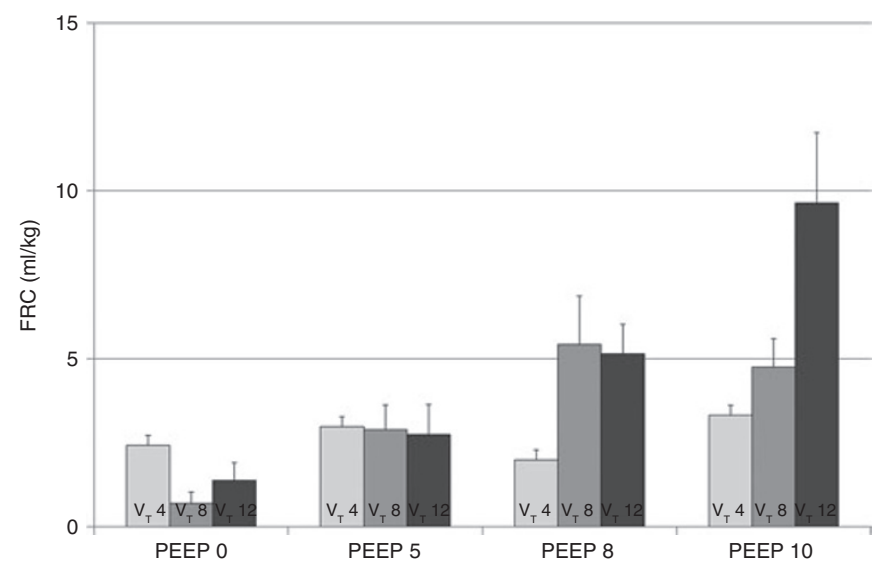

Figure 1. Functional residual capacity (FRC) after 160 inflations. Increasing both positive end-expiratory pressure (PEEP) and tidal volume $\left(\mathrm{V}_{\mathrm{T}}\right)$ resulted in a higher FRC. In all groups, FRC was still increasing after 160 inflations; typical FRC in aerated lung is $15-20 \mathrm{ml} / \mathrm{kg}$. $\mathrm{V}_{T^{\prime}}$ light gray $=4 \mathrm{ml} / \mathrm{kg} ; \mathrm{V}_{\mathrm{T}^{\prime}}$ medium gray $=8 \mathrm{ml} / \mathrm{kg} ; \mathrm{V}_{\mathrm{T}^{\prime}}$ dark gray $=12 \mathrm{ml} / \mathrm{kg}$.

Table 2. Results of linear regression

\begin{tabular}{|c|c|c|c|c|c|}
\hline \multirow[b]{2}{*}{ Variable } & \multirow[b]{2}{*}{ Inflation } & \multicolumn{2}{|c|}{ Vs. PEEP $\left(\mathrm{cmH}_{2} \mathrm{O}\right)$} & \multicolumn{2}{|c|}{ Vs. $V_{T}(\mathrm{ml} / \mathrm{kg})$} \\
\hline & & Coefficient & $P$ value & Coefficient & $P$ value \\
\hline $\mathrm{FRC}(\mathrm{ml} / \mathrm{kg})$ & 160 & 0.41 & $<0.001$ & 0.26 & 0.01 \\
\hline \multirow[t]{2}{*}{$\mathrm{PIP}\left(\mathrm{cmH}_{2} \mathrm{O}\right)$} & Initial & -0.26 & 0.01 & 0.4 & 0.01 \\
\hline & 160 & -0.6 & 0.01 & 0.5 & $<0.001$ \\
\hline \multirow[t]{2}{*}{$\operatorname{MAP}\left(\mathrm{cmH}_{2} \mathrm{O}\right)$} & Initial & 0.49 & $<0.001$ & 0.17 & 0.001 \\
\hline & 160 & 0.36 & $<0.001$ & 0.21 & $<0.001$ \\
\hline \multirow{2}{*}{$\begin{array}{l}\text { Dynamic } \\
\text { compliance } \\
\left(\mathrm{ml} / \mathrm{kg} / \mathrm{cmH}_{2} \mathrm{O}\right)\end{array}$} & Initial & 0.002 & 0.04 & 0.001 & 0.35 \\
\hline & 160 & 0.02 & $<0.001$ & 0.03 & $<0.001$ \\
\hline
\end{tabular}

For clarity, units of regression coefficients are not shown.

FRC, functional residual capacity; MAP, mean airway pressure; PEEP, positive endexpiratory pressure; PIP, peak inflating pressure; $V_{T^{\prime}}$, tidal volume. 


\section{Articles | Wheeler et al.}

Table 3. Peak inflating pressure, mean airway pressure, and dynamic compliance

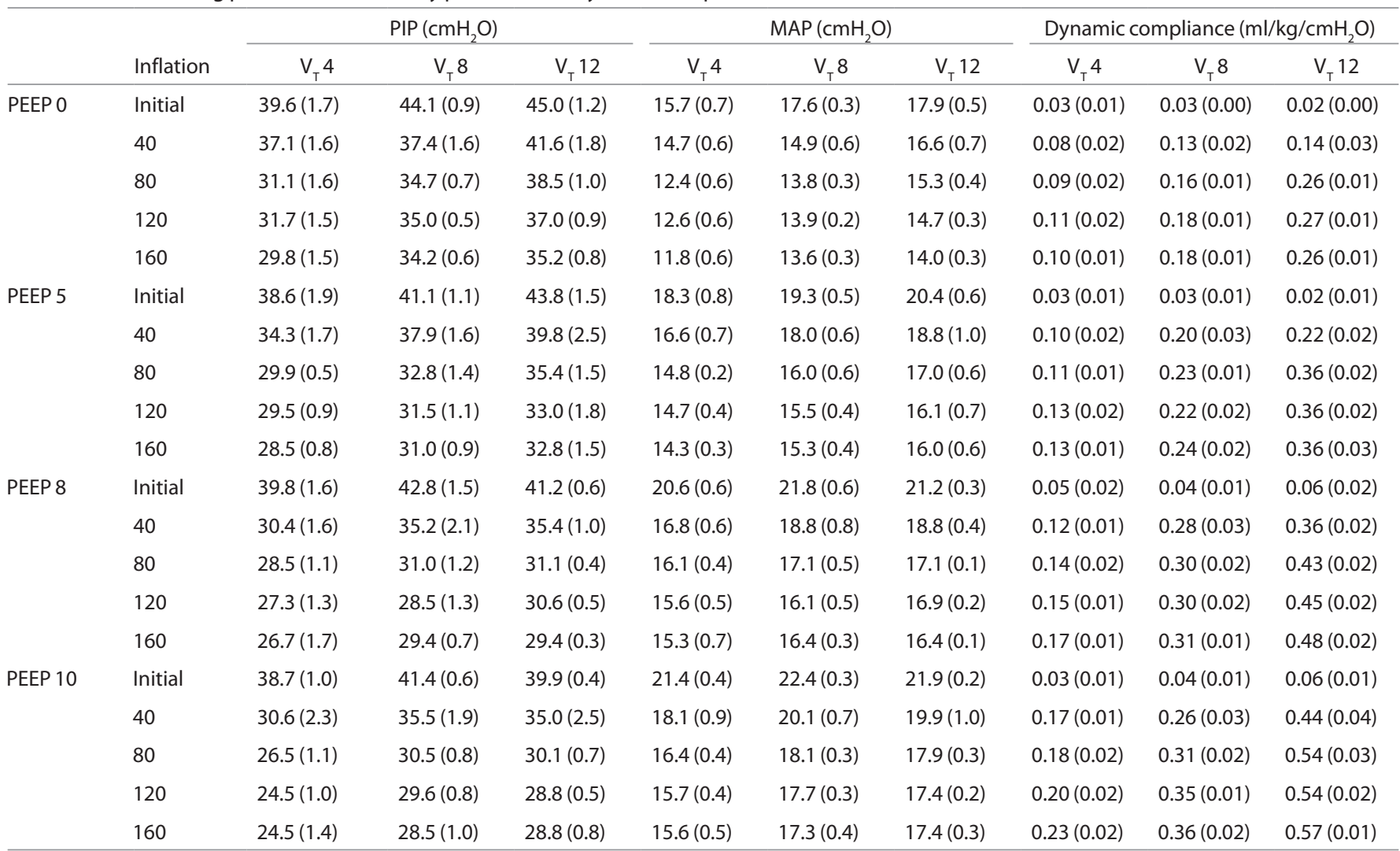

Mean (SE) data shown during initial aeration, and for inflations 40,80,120, and 160 .

$M A P$, mean airway pressure; $P E E P$, positive end-expiratory pressure; $P I P$, peak inflating pressure; $V_{T^{\prime}}$ tidal volume.

$\mathrm{PIP}_{160}$ by $6 \mathrm{cmH}_{2} \mathrm{O}(P<0.0001)$. The effect of increasing the target $\mathrm{V}_{\mathrm{T}}$ from 4 to $12 \mathrm{ml} / \mathrm{kg}$ was to increase $\mathrm{PIP}_{160}$ by $4 \mathrm{cmH}_{2} \mathrm{O}$ $(P<0.0001)$, i.e., at all levels of PEEP, the difference in PIP required to provide a $\mathrm{V}_{\mathrm{T}}$ of $12 \mathrm{ml} / \mathrm{kg}$ was only $\approx 4 \mathrm{cmH}_{2} \mathrm{O}$ higher than that required to provide $\mathrm{V}_{\mathrm{T}}=4 \mathrm{ml} / \mathrm{kg}$.

\section{Mean Airway Pressure}

Mean airway pressures (MAPs) are reported in Table 3 and Figure 3. The MAP increased with increasing PEEP and increasing $\mathrm{V}_{\mathrm{T}}$ for both the initial MAP $\left(\mathrm{MAP}_{\text {init }}\right)$ and the MAP after 160 inflations $\left(\mathrm{MAP}_{160}\right)$. The effect of $\mathrm{V}_{\mathrm{T}}$ on MAP, however, was relatively small and was effectively lost at higher PEEP levels.

The effect of increasing PEEP from 0 to $10 \mathrm{cmH}_{2} \mathrm{O}$ in different groups of pups was to increase the $\mathrm{MAP}_{\text {init }}$ by $4.9 \mathrm{cmH}_{2} \mathrm{O}(P$ $<0.001)$. The effect of increasing $\mathrm{V}_{\mathrm{T}}$ from 4 to $12 \mathrm{ml} / \mathrm{kg}$ was to increase the $\mathrm{MAP}_{\text {init }}$ by $1.3 \mathrm{cmH}_{2} \mathrm{O}(P=0.001)$, the main effect occurring between 4 and $8 \mathrm{ml} / \mathrm{kg}$.

The effect of increasing PEEP from 0 to $10 \mathrm{cmH}_{2} \mathrm{O}$ was to increase the $\mathrm{MAP}_{160}$ by $3.6 \mathrm{cmH}_{2} \mathrm{O}(P<0.001)$. The effect of increasing $\mathrm{V}_{\mathrm{T}}$ from 4 to $12 \mathrm{ml} / \mathrm{kg}$ was to increase the $\mathrm{MAP}_{160}$ by only $1.6 \mathrm{cmH}_{2} \mathrm{O}(P<0.001)$. Regression coefficients are reported in Table 2.

\section{Dynamic Compliance}

Dynamic compliance (Cd) is presented in Table 3 and Figure 4. All groups had similarly low initial $\mathrm{Cd}\left(\mathrm{Cd}_{\text {init }}\right)$. The effect of increasing PEEP from 0 to $10 \mathrm{cmH}_{2} \mathrm{O}$ was to increase $\mathrm{Cd}_{\text {init }}$ by $0.02 \mathrm{ml} / \mathrm{kg} / \mathrm{cmH}_{2} \mathrm{O}(P=0.04)$. The effect of $\mathrm{V}_{\mathrm{T}}$ on $\mathrm{Cd}_{\text {init }}$ was not statistically significant.

By 160 inflations, the $\mathrm{Cd}\left(\mathrm{Cd}_{160}\right)$ had increased at all PEEP and $\mathrm{V}_{\mathrm{T}}$ levels. Regression coefficients are reported in Table 2. The effect of increasing PEEP from 0 to $10 \mathrm{cmH}_{2} \mathrm{O}$ was to increase $\mathrm{Cd}_{160}$ by $0.20 \mathrm{ml} / \mathrm{kg} / \mathrm{cmH}_{2} \mathrm{O}(P<0.001)$. The effect of increasing $\mathrm{V}_{\mathrm{T}}$ from 4 to $12 \mathrm{ml} / \mathrm{kg}$ was to increase $\mathrm{Cd}_{160}$ by $0.30 \mathrm{ml} / \mathrm{kg} / \mathrm{cmH}_{2} \mathrm{O}(P<0.001)$. Increasing both PEEP and $\mathrm{V}_{\mathrm{T}}$ independently increased $\mathrm{Cd}$, and the effects of each were additive; the highest compliance $\left(0.57 \mathrm{ml} / \mathrm{kg} / \mathrm{cmH}_{2} \mathrm{O}\right)$ was measured at the highest PEEP $\left(10 \mathrm{cmH}_{2} \mathrm{O}\right)$ and $\mathrm{V}_{\mathrm{T}}(12 \mathrm{ml} / \mathrm{kg})$.

\section{Distribution of FRC and $V_{T}$ Within the Lung}

The gas distribution within the lung was determined from the image data and is reported in Figure 5. Data showing distribution of tidal ventilation in aerated lung from a separate set of experiments is shown for comparison (M.L. Siew, M.J. Wallace, M.J. Kitchen, et al., unpublished data); in those experiments, $72 \%$ of $\mathrm{V}_{\mathrm{T}}$ was distributed to the basal segments of the lungs, which have a larger anatomical volume.

At lower PEEPs, more gas entered the apical region of the lung during inflation, whereas more gas entered the basal regions of the lung at PEEP $=10 \mathrm{cmH}_{2} \mathrm{O}$. The effect of increasing PEEP from 0 to $10 \mathrm{cmH}_{2} \mathrm{O}$ was to increase the proportion of gas directed to the basal regions from $38 \%$ to $55 \%(P<0.001)$. 


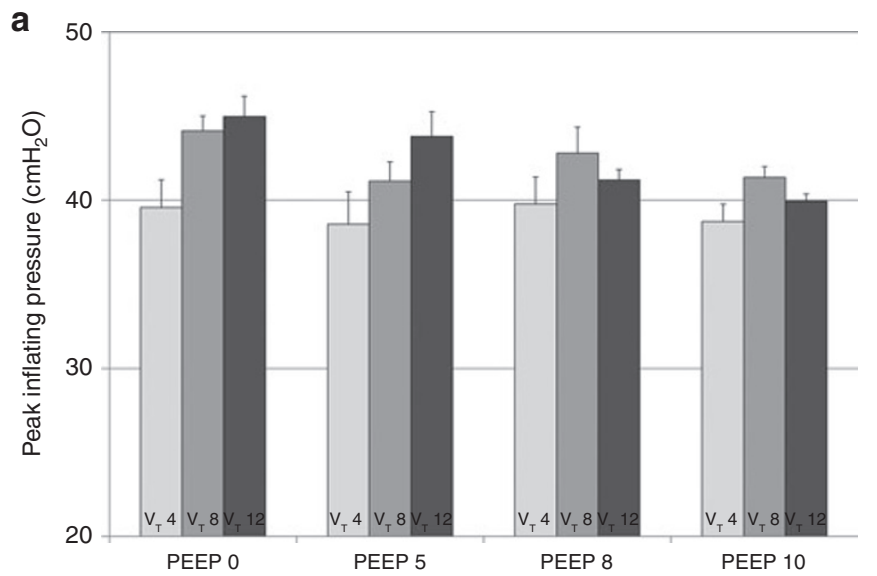

b

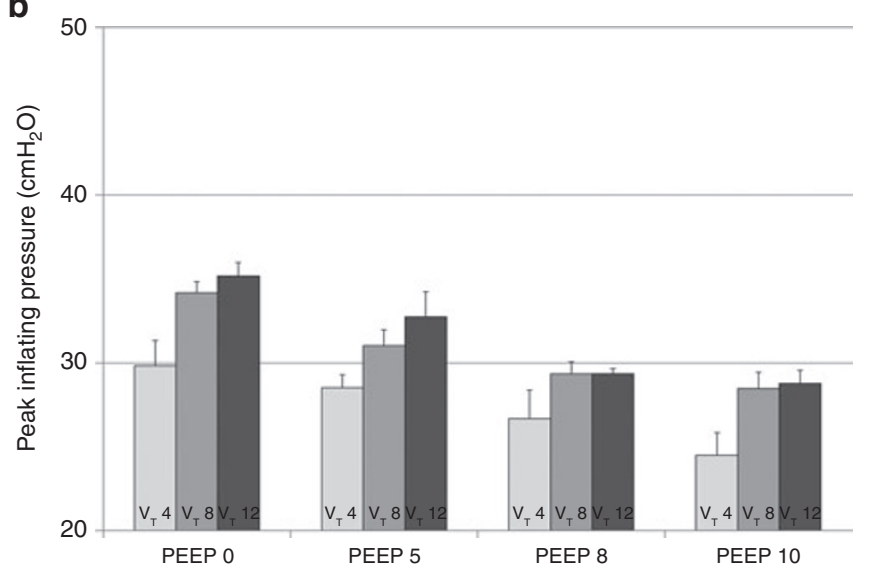

Figure 2. Maximum peak inflating pressure (PIP) (a) during the initial 40 inflations and (b) after 160 inflations. Increasing both positive endexpiratory pressure (PEEP) and tidal volume $\left(\mathrm{V}_{\mathrm{T}}\right)$ increased aeration and compliance (see Figure 3 ), and led to reduction in required PIP. The difference in PIP between the 4 and $12 \mathrm{ml} / \mathrm{kg}$ groups was $\approx 4 \mathrm{cmH}_{2} \mathrm{O}$ at all PEEPs. $\mathrm{V}_{T^{\prime}}$ light gray $=4 \mathrm{ml} / \mathrm{kg} ; \mathrm{V}_{\mathrm{T}^{\prime}}$ medium gray $=8 \mathrm{ml} / \mathrm{kg} ; \mathrm{V}_{\mathrm{T}^{\prime}}$ dark gray $=12 \mathrm{ml} / \mathrm{kg}$.

The effect of increasing $\mathrm{V}_{\mathrm{T}}$ on the distribution of gas during inflation varied with PEEP. In the PEEP 0 groups, increasing $\mathrm{V}_{\mathrm{T}}$ resulted in further increased volume to the apical region, reducing the proportion entering the basal region from $48 \%$ to $32 \%$. At PEEP 10 , increasing $\mathrm{V}_{\mathrm{T}}$ increased the distribution of tidal ventilation toward the basal region from $47 \%$ to $63 \%$ (post hoc regression: $P=0.03, R^{2}=0.94$, Figure $5 \mathrm{c}$ ).

We did not observe any effect of either PEEP or $\mathrm{V}_{\mathrm{T}}$ in the relative distribution of FRC (data not shown).

\section{DISCUSSION}

The aim of this study was to investigate the effects of different PEEP and target $\mathrm{V}_{\mathrm{T}}$ levels on FRC and gas distribution in the preterm rabbit lung. We found that increasing PEEP and $\mathrm{V}_{\mathrm{T}}$ both led to an increase in FRC and dynamic lung compliance. Increasing PEEP also improved the relative distribution of $\mathrm{V}_{\mathrm{T}}$ within the lung, increasing it to dependent regions, whereas the effect of $\mathrm{V}_{\mathrm{T}}$ was less clear.

The 2010 International Liaison Committee on Resuscitation guidelines for neonatal resuscitation recommend starting PIPs of $30 \mathrm{cmH}_{2} \mathrm{O}$ (20-25 for preterm infants), and that PEEP
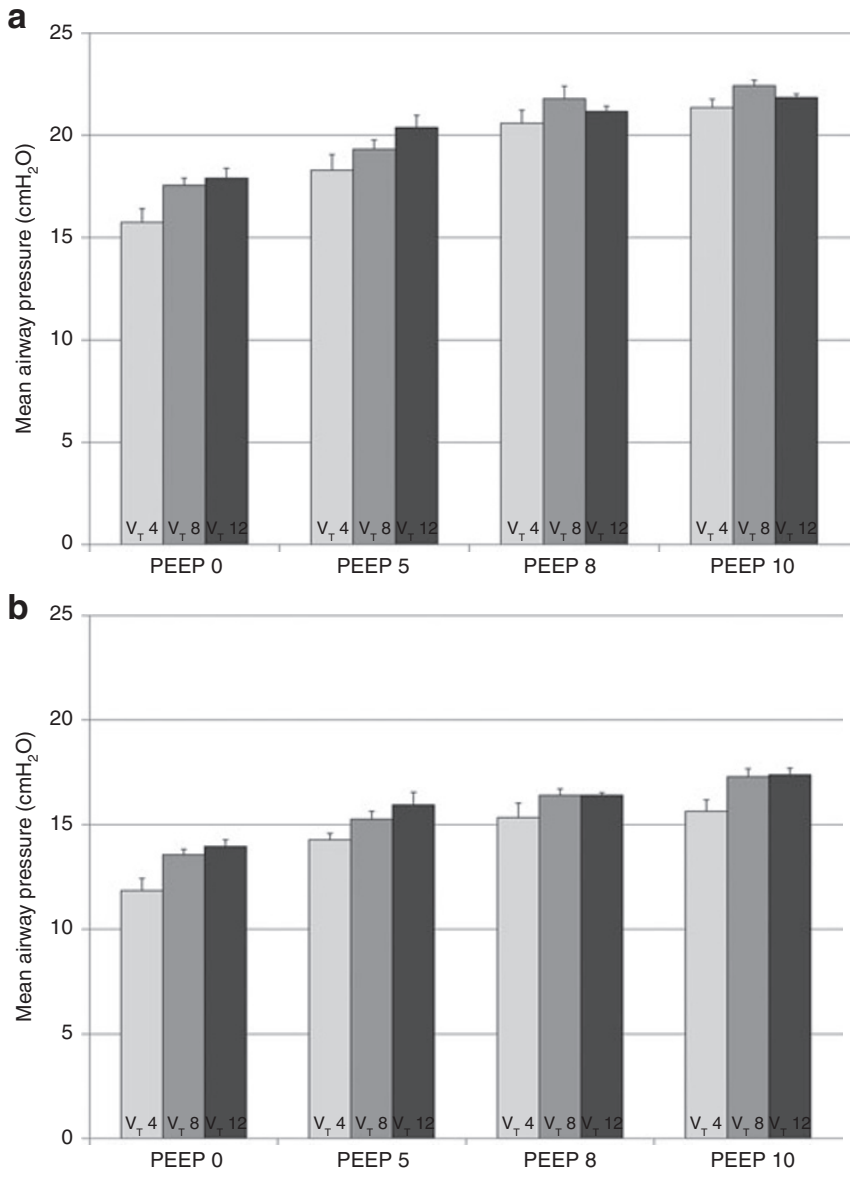

Figure 3. Mean airway pressure (MAP) (a) during initial inflations and (b) after 160 inflations. MAP reduced $\approx 5 \mathrm{cmH}_{2} \mathrm{O}$ after 160 inflations, with only $3 \mathrm{cmH}_{2} \mathrm{O}$ difference between groups. Despite a threefold difference in tidal volume $\left(\mathrm{V}_{T}\right)$, the effect of $\mathrm{V}_{T}$ on $\mathrm{MAP}_{160}$ was small. $\mathrm{V}_{T^{\prime}}$ light gray = $4 \mathrm{ml} / \mathrm{kg} ; V_{T^{\prime}}$ medium gray $=8 \mathrm{ml} / \mathrm{kg} ; V_{\mathrm{T}^{\prime}}$ dark gray $=12 \mathrm{ml} / \mathrm{kg}$. PEEP, positive end-expiratory pressure.

"should be used if suitable equipment is available" for apneic preterm infants who require PPV (2). However, a specific PEEP level is not recommended, and the guidelines warn that "high levels" of PEEP $\left(8-12 \mathrm{cmH}_{2} \mathrm{O}\right)$ may reduce pulmonary blood flow and increase the risk of pneumothoraces $(8,24)$. These guidelines draw on studies in immature animals in which high $V_{T} s$ at birth were reported to cause lung injury, impair gas exchange, and reduce lung compliance (N.H. Hillman, T.J. Moss, I. Nitsos, A.H. Jobe, unpublished data). There is a lack of evidence for many of these recommendations.

\section{FRC}

Although lung aeration is important for gas exchange after birth, uniform aeration and distribution of ventilation are also thought to be important to minimize regional overexpansion and injury $(25,26)$. Our findings indicate that when providing $\mathrm{PPV}$, adequate PEEP and $\mathrm{V}_{\mathrm{T}}$ are needed to create and establish FRC. For the very immature pups in this experiment, PEEP $\geq$ $8 \mathrm{cmH}_{2} \mathrm{O}$ and $\mathrm{V}_{\mathrm{T}} \geq 8 \mathrm{ml} / \mathrm{kg}$ were required to establish an FRC $\geq 3 \mathrm{ml} / \mathrm{kg}$. We note, however, that the FRC gained during these experiments was less than that observed in spontaneously 


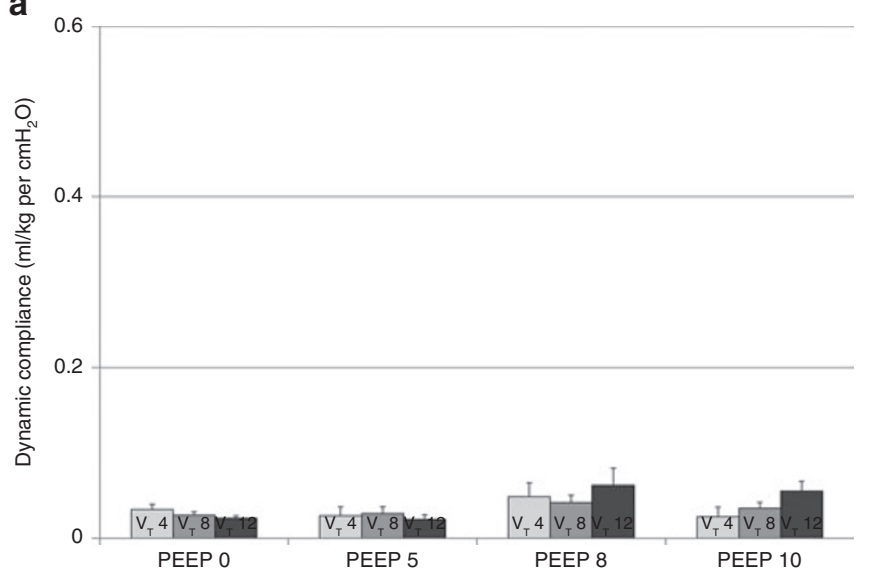

b

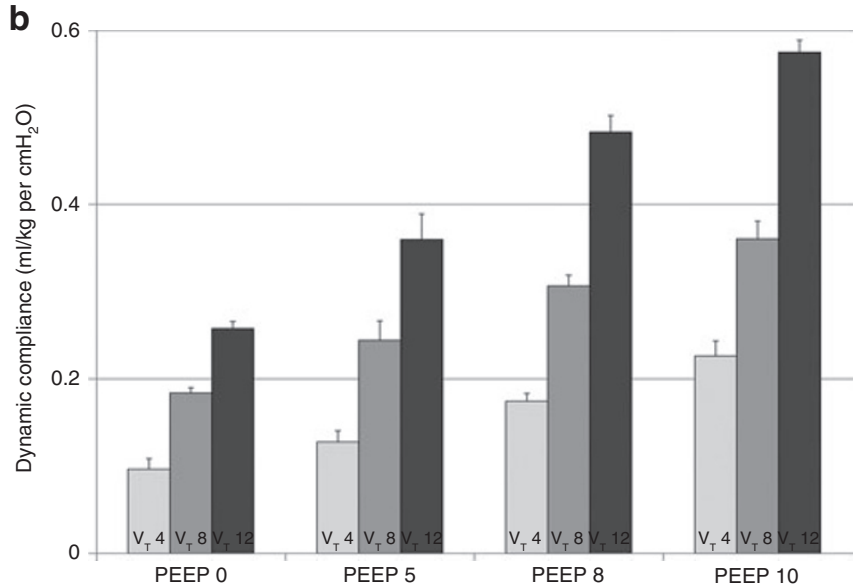

Figure 4. Dynamic compliance $(\mathrm{Cd})$, which was calculated from the tidal volume $\left(\mathrm{V}_{\mathrm{T}}\right)$ and $\triangle$ pressure (PIP - PEEP). (a) Initial $\mathrm{Cd}$ was minimal in all groups. (b) The effect of $V_{T}$ and PEEP was additive and increased $C d$ by 160 inflations. $V_{T^{\prime}}$ light gray $=4 \mathrm{ml} / \mathrm{kg} ; V_{T^{\prime}}$ medium gray $=8 \mathrm{ml} / \mathrm{kg} \mathrm{V}_{\mathrm{T}^{\prime}}$ dark gray $=12 \mathrm{ml} / \mathrm{kg}$. PEEP, positive end-expiratory pressure; PIP, peak inflating pressure.

breathing term rabbit pups (10-15 ml/kg) (27) and term human infants $(15-20 \mathrm{ml} / \mathrm{kg})(28)$. Because pups were still continuing to establish FRC after 160 inflations $(\approx 7 \mathrm{~min})$, the FRC clearly had not reached steady state by this time, and it is likely that higher FRCs would have eventually been attained (Table 1).

The effect of increasing $\mathrm{V}_{\mathrm{T}}$ on FRC depended on PEEP levels: no effect of $\mathrm{V}_{\mathrm{T}}$ was observed at the lower PEEPs, whereas at 10 PEEP we observed a marked effect of $\mathrm{V}_{\mathrm{T}}$ on FRC (Table 1 and Figure 1). Similarly, the effect of increasing PEEP on FRC was not evident at a $V_{T}$ of $4 \mathrm{ml} / \mathrm{kg}$, whereas at a higher $\mathrm{V}_{\mathrm{T}}$ $(12 \mathrm{ml} / \mathrm{kg})$ the effect of PEEP on FRC was marked. This indicates that both PEEP and an appropriate $\mathrm{V}_{\mathrm{T}}$ are required for the rapid accumulation of an appropriate FRC.

$\mathbf{V}_{\mathrm{T}}$

We have previously shown that in spontaneously breathing term newborn rabbits, the first few breaths after birth are characteristically large $(\sim 15 \mathrm{ml} / \mathrm{kg})$ and gradually reduce to $\sim 7 \mathrm{ml} / \mathrm{kg}$ after the first 100 breaths (19). In human neonates, $\mathrm{V}_{\mathrm{T}} \mathrm{s}$ of $6.4(4.1) \mathrm{ml} / \mathrm{kg}$ have been observed in term infants and
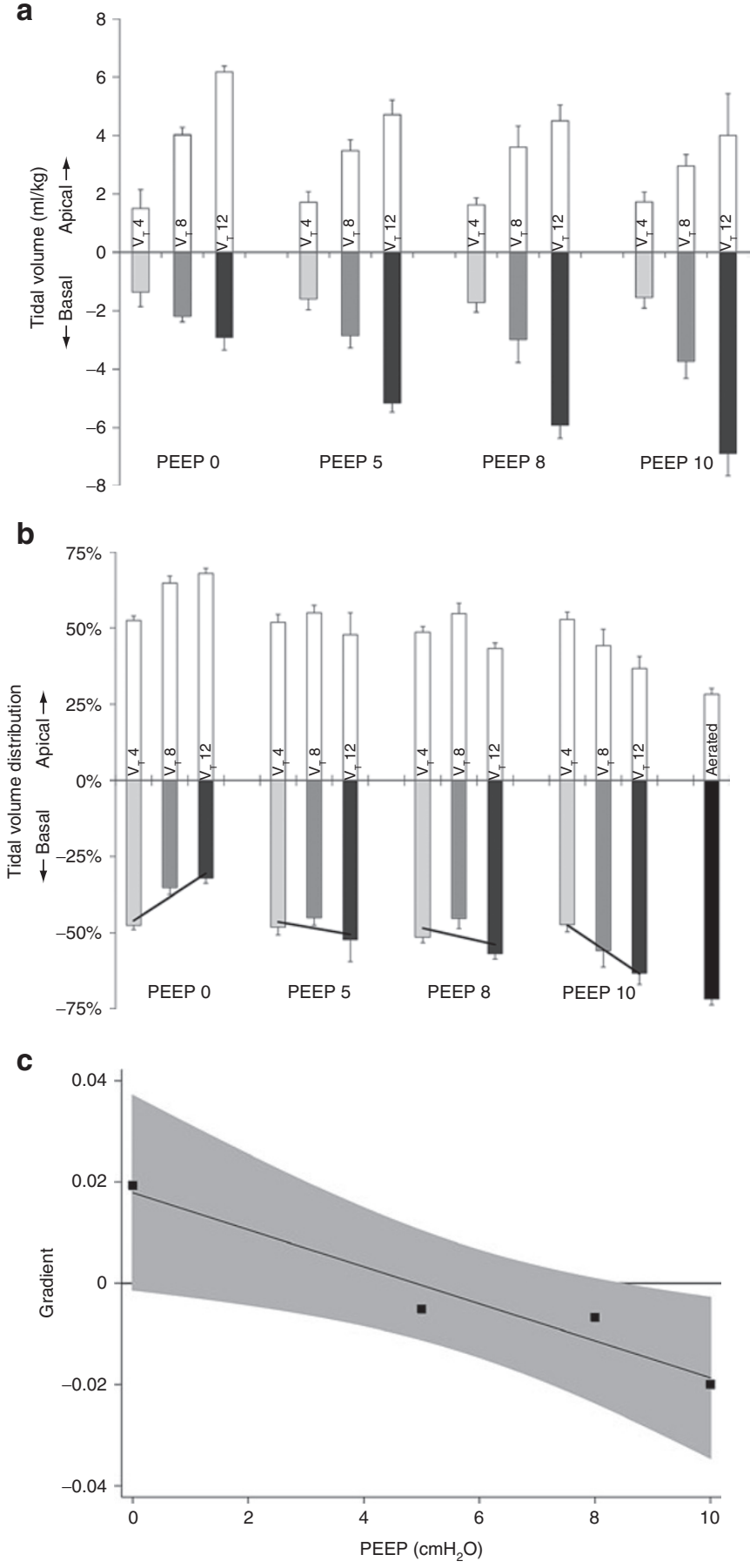

Figure 5. Mean (SE) tidal volume $\left(\mathrm{V}_{\mathrm{T}}\right)$ distribution after 160 inflations. (a) Absolute volume measurements $(\mathrm{ml} / \mathrm{kg})$ distributed to the apical and basal regions. (b) Percentage distribution of $V_{T}$ distributed to the apical and basal regions, compared with data from aerated lung with homogenous ventilation. Increasing positive-end expiratory pressure (PEEP) increased $V_{T}$ distribution to the lower lung regions (which have a larger volume and are preferentially ventilated during normal breathing). At lower PEEPs (with lower functional residual capacity (FRC)), increasing $V_{T}$ preferentially increased ventilation of the upper regions. At higher PEEPs (with a higher FRC), increasing $V_{T}$ increased ventilation of the lower regions. (c) Linear regression of the gradients in $\mathbf{b}$ at each of the four PEEP settings (gradient $=-0.36 \mathrm{PEEP}+1.79\left(P=0.03, R^{2}=0.94\right)$ ). $\mathrm{V}_{\mathrm{T}^{\prime}}$ light gray $=4 \mathrm{ml} / \mathrm{kg} ; \mathrm{V}_{\mathrm{T}^{\prime}}$ medium gray $=8 \mathrm{ml} / \mathrm{kg} ; \mathrm{V}_{\mathrm{T}^{\prime}}$ dark gray $=12 \mathrm{ml} / \mathrm{kg} ;$ black, aerated lung. 
$6.7(3.9) \mathrm{ml} / \mathrm{kg}$ in preterm infants, although it is unlikely that the very first breaths after birth were recorded in this study (29). In a separate study of babies receiving continuous positive airway pressure at birth, a variety of different respiratory patterns were observed with $\mathrm{V}_{\mathrm{T}}$ ranging from mean (SD) 3.1 (1.7) to $7.5(4.2) \mathrm{ml} / \mathrm{kg}$ (30). Although evidence is lacking in preterm human infants, spontaneously breathing newborn rabbits appear to use large $\mathrm{V}_{\mathrm{T}} \mathrm{s}(\approx 15 \mathrm{ml} / \mathrm{kg})$ at the onset of air breathing, which gradually decrease with increasing breath number. On the basis of our observations, this would be expected to facilitate FRC recruitment.

Although large $\mathrm{V}_{\mathrm{T}} \mathrm{s}$ facilitate $\mathrm{FRC}$ recruitment, they are largely thought to be injurious to the lung in newborn infants receiving respiratory support $(31,32)$. Indeed, only six inflations of $35-40 \mathrm{ml} / \mathrm{kg}$ were sufficient to impair the response to surfactant and induce histological evidence of lung injury (3). Our data suggest that the combination of a relatively large $V_{T}$ with little or no PEEP is likely to be even more injurious than when combined with a high PEEP. With no PEEP, the vast majority of the $V_{T}$ was primarily distributed to the smaller apical lobes; this is likely to induce regional overdistension injury in those areas. By contrast, the delivery of a relatively large $V_{T}$ combined with a high PEEP in the initial resuscitation period distributed the air in a similar fashion to that observed in a well-aerated lung.

Clearly, the optimal $\mathrm{V}_{\mathrm{T}} \mathrm{s}$ that should be used during the early stages of resuscitation at birth are unknown. Although an arbitrary range of $4-8 \mathrm{ml} / \mathrm{kg}$ is considered to be the optimal $\mathrm{V}_{\mathrm{T}}$ range to target when ventilating preterm human infants, a recent study has demonstrated that many of the volumes delivered during resuscitation are inadvertently well outside this range (33). It is clear that some spontaneous breathing infants initiate tidal breathing exceeding $8 \mathrm{ml} / \mathrm{kg}(29,30)$. In newborn rabbits, $V_{T}$ reduces as aeration occurs (19). During PPV, continued delivery of high $\mathrm{V}_{\mathrm{T}} \mathrm{s}$ is likely to be injurious.

\section{PIPs and Dynamic Pulmonary Compliance}

For all levels of PEEP and $\mathrm{V}_{\mathrm{T}}$, the PIPs required to initiate lung aeration were high ( $40-45 \mathrm{cmH}_{2} \mathrm{O}$ ), which was likely to be due to the initial presence of liquid in the airways rather than any other factor $(19,34)$. However, the PIP required to achieve a set $\mathrm{V}_{\mathrm{T}}$ markedly and rapidly decreased as soon as the lung began to aerate. During this time, dynamic lung compliance was greatest in pups receiving the largest PEEP $\left(10 \mathrm{cmH}_{2} \mathrm{O}\right)$ and/ or $\mathrm{V}_{\mathrm{T}}(12 \mathrm{ml} / \mathrm{kg})$, resulting in much lower PIPs. This reflects more effective airway liquid clearance, resulting in larger lung gas volumes. Although the PIPs required during the initial 40 inflations were higher than those routinely used in human infants, they are not dissimilar to those used in preterm lambs (31). Similarly, previous studies have investigated the effects of PEEP on pulmonary function in preterm lambs and found that lambs ventilated at high PEEP $\left(12 \mathrm{cmH}_{2} \mathrm{O}\right)$ initially had better lung function but all developed pneumothoraces and died within $90 \mathrm{~min}$ (35). None of the pups developed pneumothoraces in our study, but they were ventilated for only a relatively short period. Because the characteristics of the lung are very different during the first few minutes after ventilation onset, as compared with when it is fully aerated, continued PEEP of $10 \mathrm{cmH}_{2} \mathrm{O}$ may have eventually resulted in pneumothoraces. Therefore, optimal PEEP levels may differ with time after birth.

\section{Distribution of Tidal Ventilation}

The distribution of tidal ventilation with increasing $V_{T}$ at different PEEP levels was consistent within a group, but varied between groups. In particular, at PEEP 0 , increasing the $\mathrm{V}_{\mathrm{T}}$ increased the distribution of incoming air into the apical regions of the lung. By contrast, at PEEP 10, increasing the $\mathrm{V}_{\mathrm{T}}$ increased the distribution of incoming air into the basal regions of the lung. It is possible that this finding explains the marked increase in lung compliance at higher PEEPs and $\mathrm{V}_{\mathrm{T}} \mathrm{s}$. Given that the basal regions of the lung are much larger and have a greater potential gas volume, we suggest that higher PEEPs effectively allow the incoming tidal ventilation to have access to and ventilate these dependent regions, thereby greatly increasing the ventilated gas volume of the lung.

Thus, it is clinically plausible that by increasing FRC and compliance, the combination of higher PEEPs and $\mathrm{V}_{\mathrm{T}}$ during the immediate newborn period promoted a more physiological distribution of tidal ventilation. However, future studies should examine the effect of these strategies on the adequacy of gas exchange and on lung injury.

\section{Limitations and Applicability}

This study was designed to examine the physiological principles of establishing FRC soon after birth, and particularly the roles of $\mathrm{V}_{\mathrm{T}}$ and PEEP. We used a preterm animal model because these relationships cannot ethically be thoroughly examined in human infants. The premature rabbits were sedated, surgically intubated, immersed in warm water (with the head out of the water), and ventilated in an upright orientation, and were not exposed to maternal steroids. As such, these experiments were not intended to replicate clinical practice, but to specifically examine the inter-relationship between $\mathrm{V}_{\mathrm{T}}$ and PEEP on FRC, lung compliance, and the distribution of tidal ventilation, as these relationships are likely to be similar in humans.

The relatively low FRCs measured during this experiment are likely to result from a number of factors, particularly the extremely immature nature of the neonatal rabbits used (27 $\mathrm{d}$ gestational age), and the fact that neither antenatal steroids nor postnatal surfactant were administered. Because we used a relatively long expiratory phase (1.5 s) to facilitate image acquisition, there was likely to be a greater reliance on PEEP, as compared with other factors such as inflation, for maintaining FRC. However, because the same ventilation parameters (except the $\mathrm{V}_{\mathrm{T}}$ and PEEP changes) were used for all pups, we do not believe this would have biased the results.

\section{Implications for Clinical Practice}

Although the physiological principles are likely to be similar in human infants, the ventilation parameters used (e.g., PIPs and PEEPs) may not be directly comparable between preterm rabbits and humans. In performing this volume-targeted strategy 
with the advantage of an endotracheal tube present at birth, we needed to adjust the initial PIPs quickly, both up and down, particularly over the initial 40 inflations. During ongoing ventilation, a difference in PIP of only $\sim 4 \mathrm{cmH}_{2} \mathrm{O}$ increased $\mathrm{V}_{\mathrm{T}}$ from 4 to $12 \mathrm{ml} / \mathrm{kg}$. This indicates that it may be difficult to achieve specific $\mathrm{V}_{\mathrm{T}} \mathrm{s}$ manually during resuscitation without appropriate volume-targeted devices. Current guidelines for resuscitating preterm infants recommend starting PIPs of $20-25 \mathrm{cmH}_{2} \mathrm{O}$, and adjusting according to clinical response (2). However, because the effects of any particular PIP are highly variable and can change quickly with time, monitoring the $\mathrm{V}_{\mathrm{T}}$ administered would seem to be important.

Furthermore, the guidelines caution against the use of higher PEEPs, citing animal studies resulting in increased pneumothoraces and reduced pulmonary blood flow. However, these adverse outcomes occurred beyond $30 \mathrm{~min}$ of age, after the lungs were initially aerated, and may not be applicable to the immediate newborn period when the lung is partially liquidfilled and its mechanics are very different. Therefore, we suggest that the use of higher PEEPs during the initial resuscitation of extremely preterm neonates should be evaluated further.

\section{Conclusion}

The effects of PEEP and $\mathrm{V}_{\mathrm{T}}$ on lung aeration were examined using a rabbit model of extreme prematurity. Both PEEP and $\mathrm{V}_{\mathrm{T}}$ have independent but additive effects on FRC recruitment, lung mechanics, and the distribution of ventilation during the immediate newborn period. Specifically, increasing PEEP and $\mathrm{V}_{\mathrm{T}}$ levels markedly increase FRC, improve lung compliance, and increase the proportion of ventilation entering the larger basal regions of the lung. Future studies should investigate the effects of these strategies on acute lung injury.

\section{METHODS}

\section{Animal Experiments}

All procedures were approved by Monash University and SPring-8 Synchrotron Animal Ethics Committees. Pregnant New Zealand white rabbits were studied at $27 \mathrm{~d}$ gestational age (term $=32 \mathrm{~d}$ ). Antenatal steroids were not used. Anesthesia of the doe was induced using propofol $(12 \mathrm{mg} / \mathrm{kg}$ bolus, $100 \mathrm{mg} / \mathrm{kg} / \mathrm{h}$ infusion; Rapinovet, ScheringPlough Animal Health, Millsboro, DE) and maintained with inhaled isofluorane (1-2\%) following intubation. Pups were partially delivered sequentially by hysterotomy, retaining a patent umbilical cord and with amniotic membranes over the nose and mouth to prevent air entering the lungs. Pups were sedated with sodium pentobarbitone (Nembutal, $0.1 \mathrm{mg}$ i.p., Abbott Laboratories, North Chicago, IL), and local analgesia was applied to the neck (Xylocaine; 5\% lignocaine, AstraZeneca, Södertälje, Sweden) before they were intubated surgically via a tracheostomy using an 18-gauge plastic canula as an endotracheal tube. This was capped to prevent air entering the lungs before PPV commenced. The umbilical cord was cut and the pup placed in a purpose-built water plethysmograph (34) to record respiratory function during imaging. After the experiment, rabbits and their pups were humanely killed using an overdose of sodium pentabarbitone (>100 mg/kg).

\section{Experimental Protocol}

Changes in lung volume were measured with a head-out water-filled plethysmograph (prewarmed to $39^{\circ} \mathrm{C}$ ) as previously described (36). Using a purpose-built, small animal ventilator (Monash University, Clayton, Australia) (37), pups were ventilated initially with a PIP of 35 $\mathrm{cmH}_{2} \mathrm{O}$, adjusted to achieve the desired $\mathrm{V}_{\mathrm{T}}$. Ventilation was provided at a rate of 24 inflations/min (1.0 s inflation and $1.5 \mathrm{~s}$ deflation) for
7 min (160 inflations). These times were used so that images could be acquired during both inflation (three images) and deflation (four images). Imaging was synchronized to the onset of each inspiration to ensure consistent image acquisition through the respiratory cycle. Twelve groups of pups ( $n=5$ per group) were studied, with different groups receiving one of three different $\mathrm{V}_{\mathrm{T}} \mathrm{s}(4,8$, or $12 \mathrm{ml} / \mathrm{kg})$ and one of four different PEEP levels $\left(0,5,8\right.$, or $\left.10 \mathrm{cmH}_{2} \mathrm{O}\right)$.

\section{Phase Contrast X-Ray Imaging}

Phase contrast X-ray imaging techniques were used to measure lung gas volumes and the regional distribution of ventilation within and between successive breaths as previously reported (23). These lung gas volume measurements are accurate to within $25 \mu \mathrm{l}$, closely agreeing with plethysmograph measurements (23). The X-ray energy used was $24 \mathrm{keV}$ and the imaging detector was placed $3 \mathrm{~m}$ downstream from the pups to optimize the phase contrast effects. Imaging was synchronized with mechanical ventilation using a short exposure time $(40 \mathrm{~ms})$, which when combined with relatively long inspiratory $(1.0 \mathrm{~s})$ and expiratory $(1.5 \mathrm{~s})$ times minimized motion blur. The detector was a Hamamatsu C9300-124F21 CCD camera (Hamamatsu Photonics, Shizuoka Prefecture, Japan) with a 1.8:1 ratio Fiber Optic Taper bonded to the CCD chip (16.2 $\mu \mathrm{m}$ effective pixel size). Radiation exposure to the pup was minimized by the use of a presubject shutter.

\section{Data Collection}

Plethysmograph measurements, ventilation parameters, and image timing data were collected at $1,000 \mathrm{~Hz}$ using PowerLab ADCs and LabChart Software version 7 (both ADInstruments, Sydney, Australia).

\section{Image Analysis}

Distribution of tidal ventilation was determined from image analysis as previously described and validated (23). The position of the pup was tracked using skeletal landmarks and a fiducial marker. Each frame was partitioned into quadrants: vertically through the spine and horizontally at the level of the seventh rib. The proportion of the $\mathrm{V}_{\mathrm{T}}$ distributed to the apical and basal regions of the lung was calculated and compared with measures separately obtained from fully aerated and homogenously ventilated lungs of pups of similar maturity; mean (SD) FRC 31 (12) $\mathrm{ml} / \mathrm{kg}$ (M.L. Siew, M.J. Wallace, M.J. Kitchen, et al., unpublished data).

\section{Analysis of Physiological Data}

FRC was determined from plethysmograph data after each inflation, and defined as the volume of gas in the lung at end expiration. FRC was determined at 40,80,120, and 160 inflations by averaging five consecutive measurements, e.g., the FRC for inflation 80 was calculated by averaging end-expiratory measurements of inflations 78-82.

$\mathrm{V}_{\mathrm{T}}$ was defined as the volume change for each inflation, and the $\triangle$ pressure was defined as (PIP - PEEP). MAP was calculated using PIP, PEEP, and the I:E ratio. Cd was determined by dividing the $\mathrm{V}_{\mathrm{T}}$ by the $\Delta$ pressure. These parameters were determined as five-point averages for the same inflations as the FRC measurements.

From previous experience of ventilating neonatal rabbits of similar immaturity, we expected to initially increase the PIP to achieve initial tidal ventilation. Most pups did not have a stable $\mathrm{V}_{\mathrm{T}}$ until 40 inflations, and so data from inflations 40 to 160 were used to define the mean delivered $V_{T}$. Data from the first 40 inflations were used to determine the $\mathrm{PIP}_{\text {init' }}^{\mathrm{T}}$, defined as the maximum PIP required to achieve initial aeration. $\mathrm{MAP}_{\text {init }}$ and $\mathrm{Cd}_{\text {init }}$ were calculated at the corresponding inflation.

\section{Statistics}

No data were available to determine a sample size calculation. However, based on the expected differences and similar experiments performed previously $(9,19,21,22)$, we used a sample size of five pups per group. Recorded data were analyzed using LabChart (ADInstruments, Sydney, Australia) and Excel (version 2007, Microsoft, Redmond, WA). Statistics were performed using Stata (version IC 10.1; Stata Corp, College Station, TX). A $P$ value of $<0.05$ was considered to be statistically significant.

We performed linear regression for each major outcome against $\mathrm{V}_{\mathrm{T}}$ and PEEP. Post hoc, after reviewing the nonlinear effect of $\mathrm{V}_{\mathrm{T}}$ on 
the distribution of ventilation into apical and basal lobes at increasing PEEP levels, we performed regression of the gradient of $\mathrm{V}_{\mathrm{T}}$ distribution at each PEEP setting.

\section{ACKNOWLEDGMENT}

The authors acknowledge the support of the SPring-8 Synchrotron Radiation Facility, Japan, in providing beam time for these experiments.

\section{STATEMENT OF FINANCIAL SUPPORT}

This project was funded by Australian National Health and Medical Research Council (NHMRC) grant 384100 and supported by the Victorian Government's Operational Infrastructure Support Program. Travel funding was provided by the International Synchrotron Access Program managed by the Australian Synchrotron and funded by the Australian Government. K.W. is supported by a Monash University International Graduate Scholarship. P.D. and S.H. are in receipt of NHMRC research fellowships. M.K. is the recipient of an Australian Research Fellowship funded by the Australian Research Council.

Disclosure: C.M. is a consultant to Dräger Medical, Lübeck, Germany. This company was not involved with the study design, conduct, data analysis, or preparation of the manuscript and did not contribute financial support.

\section{REFERENCES}

1. Laws P, Sullivan EA. Australia's mothers and babies 2007. Perinatal statistics series no. 23. Cat. no. PER 48. Sydney, Australia: Australian Institute of Health and Welfare (AIHW) National Perinatal Statistics Unit, 2009.

2. Perlman JM, Wyllie J, Kattwinkel J, et al.; Neonatal Resuscitation Chapter Collaborators. Part 11: Neonatal resuscitation: 2010 International Consensus on Cardiopulmonary Resuscitation and Emergency Cardiovascular Care Science With Treatment Recommendations. Circulation 2010;122:16 Suppl 2:S516-38.

3. Björklund LJ, Ingimarsson J, Curstedt T, et al. Manual ventilation with a few large breaths at birth compromises the therapeutic effect of subsequent surfactant replacement in immature lambs. Pediatr Res 1997;42:348-55.

4. Wallace MJ, Probyn ME, Zahra VA, et al. Early biomarkers and potential mediators of ventilation-induced lung injury in very preterm lambs. Respir Res 2009;10:19.

5. Dreyfuss D, Saumon G. Role of tidal volume, FRC, and end-inspiratory volume in the development of pulmonary edema following mechanical ventilation. Am Rev Respir Dis 1993;148:1194-203.

6. Dreyfuss D, Saumon G. Ventilator-induced lung injury: lessons from experimental studies. Am J Respir Crit Care Med 1998;157:294-323.

7. Muscedere JG, Mullen JB, Gan K, Slutsky AS. Tidal ventilation at low airway pressures can augment lung injury. Am J Respir Crit Care Med 1994;149:1327-34.

8. Probyn ME, Hooper SB, Dargaville PA, et al. Positive end expiratory pressure during resuscitation of premature lambs rapidly improves blood gases without adversely affecting arterial pressure. Pediatr Res 2004;56:198-204.

9. Siew ML, Te Pas AB, Wallace MJ, et al. Positive end-expiratory pressure enhances development of a functional residual capacity in preterm rabbits ventilated from birth. J Appl Physiol 2009;106:1487-93.

10. te Pas AB, Davis PG, Hooper SB, Morley CJ. From liquid to air: breathing after birth. J Pediatr 2008;152:607-11.

11. Jain L, Dudell GG. Respiratory transition in infants delivered by cesarean section. Semin Perinatol 2006;30:296-304.

12. Jain L, Eaton DC. Physiology of fetal lung fluid clearance and the effect of labor. Semin Perinatol 2006;30:34-43.

13. Bland RD. Lung liquid clearance before and after birth. Semin Perinatol 1988;12:124-33.

14. Bland RD, Nielson DW. Developmental changes in lung epithelial ion transport and liquid movement. Annu Rev Physiol 1992;54:373-94.

15. O'Brodovich H, Hannam V, Seear M, Mullen JB. Amiloride impairs lung water clearance in newborn guinea pigs. J Appl Physiol 1990;68:1758-62.
16. Hummler E, Planès $\mathrm{C}$. Importance of $\mathrm{ENaC}$-mediated sodium transport in alveolar fluid clearance using genetically-engineered mice. Cell Physiol Biochem 2010;25:63-70.

17. Hummler E, Barker P, Beermann F, et al. Role of the epithelial sodium channel in lung liquid clearance. Chest 1997;111:Suppl 6:113S.

18. Barker PM, Olver RE. Invited review: clearance of lung liquid during the perinatal period. J Appl Physiol 2002;93:1542-8.

19. Siew ML, Wallace MJ, Kitchen MJ, et al. Inspiration regulates the rate and temporal pattern of lung liquid clearance and lung aeration at birth. J Appl Physiol 2009;106:1888-95.

20. Bland RD. Lung epithelial ion transport and fluid movement during the perinatal period. Am J Physiol 1990;259(2 Pt 1):L30-7.

21. te Pas AB, Siew M, Wallace MJ, et al. Effect of sustained inflation length on establishing functional residual capacity at birth in ventilated premature rabbits. Pediatr Res 2009;66:295-300.

22. te Pas $A B$, Siew M, Wallace MJ, et al. Establishing functional residual capacity at birth: the effect of sustained inflation and positive end-expiratory pressure in a preterm rabbit model. Pediatr Res 2009;65:537-41.

23. Kitchen MJ, Lewis RA, Morgan MJ, et al. Dynamic measures of regional lung air volume using phase contrast $\mathrm{x}$-ray imaging. Phys Med Biol 2008;53:6065-77.

24. Polglase GR, Hooper SB, Gill AW, et al. Cardiovascular and pulmonary consequences of airway recruitment in preterm lambs. J Appl Physiol 2009;106:1347-55.

25. Rimensberger PC. Neonatal respiratory failure. Curr Opin Pediatr 2002;14:315-21.

26. Lachmann B. Open up the lung and keep the lung open. Intensive Care Med 1992;18:319-21.

27. Lachmann B, Grossmann G, Nilsson R, Robertson B. Lung mechanics during spontaneous ventilation in premature and fullterm rabbit neonates. Respir Physiol 1979;38:283-302.

28. Vilstrup CT, Björklund LJ, Larsson A, Lachmann B, Werner O. Functional residual capacity and ventilation homogeneity in mechanically ventilated small neonates. J Appl Physiol 1992;73:276-83.

29. te Pas AB, Wong C, Kamlin CO, Dawson JA, Morley CJ, Davis PG. Breathing patterns in preterm and term infants immediately after birth. Pediatr Res 2009;65:352-6.

30. te Pas AB, Davis PG, Kamlin CO, Dawson J, O’Donnell CP, Morley CJ. Spontaneous breathing patterns of very preterm infants treated with continuous positive airway pressure at birth. Pediatr Res 2008;64: 281-5.

31. Hillman NH, Moss TJ, Kallapur SG, et al. Brief, large tidal volume ventilation initiates lung injury and a systemic response in fetal sheep. Am J Respir Crit Care Med 2007;176:575-81.

32. Wada K, Jobe AH, Ikegami M. Tidal volume effects on surfactant treatment responses with the initiation of ventilation in preterm lambs. J Appl Physiol 1997;83:1054-61.

33. Schmölzer GM, Kamlin OC, O’Donnell CP, Dawson JA, Morley CJ, Davis PG. Assessment of tidal volume and gas leak during mask ventilation of preterm infants in the delivery room. Arch Dis Child Fetal Neonatal Ed 2010;95:F393-7.

34. Hooper SB, Kitchen MJ, Wallace MJ, et al. Imaging lung aeration and lung liquid clearance at birth. FASEB J 2007;21:3329-37.

35. Probyn ME, Hooper SB, Dargaville PA, McCallion N, Harding R, Morley CJ. Effects of tidal volume and positive end-expiratory pressure during resuscitation of very premature lambs. Acta Paediatr 2005;94:1764-70.

36. Hooper SB, Kitchen MJ, Siew ML, et al. Imaging lung aeration and lung liquid clearance at birth using phase contrast X-ray imaging. Clin Exp Pharmacol Physiol 2009;36:117-25.

37. Kitchen MJ, Habib A, Fouras A, et al. A new design for high stability pressure-controlled ventilation for small animal lung imaging. J Inst 2010;5 T02002:1-11. 